\title{
Cetuximab-induced insulin-like growth factor receptor I activation mediates cetuximab resistance in gastric cancer cells
}

\author{
$\mathrm{XIN} \mathrm{LI}^{1}, \mathrm{LING} \mathrm{XU}^{1}$, HEMING LI $^{1}$, LEI ZHAO $^{1}$, YING LUO $^{1}$, \\ ZHITU ZHU ${ }^{2}$, YUNPENG LIU ${ }^{1}$ and XIUJUAN QU ${ }^{1}$ \\ ${ }^{1}$ Department of Medical Oncology, The First Hospital of China Medical University, Shenyang, Liaoning 110001; \\ ${ }^{2}$ Department of Medical Oncology, The First Affiliated Hospital of Liaoning Medical University, \\ Jinzhou, Liaoning 121001, P.R. China
}

Received December 6, 2013; Accepted September 12, 2014

DOI: $10.3892 / \mathrm{mmr} .2015 .3245$

\begin{abstract}
Epidermal growth factor receptor (EGFR) and insulin-like growth factor receptor-I (IGF-IR) are frequently overexpressed in gastric cancer cells. However, these cells are resistant to the anti-EGFR monoclonal antibody cetuximab. The aim of the present study was to determine whether cetuximab resistance in gastric cancer cells resulted from activation of the IGF-IR signaling pathway by cetuximab. The results demonstrated that EGFR phosphorylation was markedly inhibited in gastric cancer cell lines (SGC7901 and MGC803) which possessed functional K-ras and BRAF following treatment with cetuximab. However, cetuximab treatment did not diminish cell viability; by contrast, IGF-IR activation was observed. Knockdown of IGF-IR or the use of an IGF-IR inhibitor were found to increase the sensitivity of gastric cancer cells to cetuximab. Furthermore, cetuximab induced phosphorylation of the non-receptor tyrosine kinase c-steroid receptor co-activator (Src). Treatment of gastric cancer cells with a Src inhibitor was shown to significantly reduce cetuximab-induced phosphorylation of IGF-IR as well as Src, which resulted in enhanced sensitivity to cetuximab treatment. In conclusion, the results of the present study demonstrated that cetuximab-induced IGF-IR activation was involved in cetuximab resistance in gastric cancer cells and that Src was an important mediator for IGF-IR activation.
\end{abstract}

\section{Introduction}

Gastric cancer is highly prevalent in East Asia, with $42 \%$ of cases occurring in China (1). The median life expectancy of gastric

Correspondence to: Professor Yunpeng Liu or Professor Xiujuan Qu, Department of Medical Oncology, The First Hospital of China Medical University, 155 North Nanjing Street, Heping, Shenyang, Liaoning 110001, P.R. China

E-mail: cmuliuyunpeng@hotmail.com

E-mail: qu_xiujuan@hotmail.com

Key words: insulin-like growth factor receptor-I, cetuximab, steroid receptor co-activator, gastric cancer cancer patients following diagnosis is $<1$ year; however, combination chemotherapy treatments have the potential to extend the survival rate of advanced stage patients (2-8). Therefore, using chemotherapy in conjunction with effective targeting of key factors may be beneficial for improving the clinical outcome of gastric cancer patients. A phase III clinical trial demonstrated that the use of chemotherapy in conjunction with a human epidermal growth factor receptor 2 (HER2)-specific monoclonal antibody (trastuzumab) significantly improved the overall survival rate of patients with HER2-neu overexpressing gastroesophageal junction cancer compared with that of chemotherapy alone (7). However, overexpression of Her-2 is present in only $10-20 \%$ of gastric cancer patients (9) and therefore, this combination treatment may not be beneficial for the majority of patients. Cetuximab (C225), an anti-epidermal growth factor receptor (EGFR) monoclonal antibody, has been widely used in combination with chemotherapy for the treatment of various cancer types, including metastatic colorectal cancers that retain wild-type $K$-ras and $B R A F$ genes, squamous cell carcinoma of the head and neck as well as non-small cell lung cancer (NSCLC) (10-12). The majority of gastric cancers overexpress EGFR (13), while retaining wild-type $K$-ras and $B R A F$ genes $(14,15)$. Phase II clinical studies have shown that cetuximab in combination with chemotherapy delayed the progression of gastric cancer in patients, with an acceptable response rate $(13,16-18)$. However, two additional trials failed to demonstrate significant improvement in overall patient survival with use of the anti-EGFR antibodies cetuximab or panitumumab in combination with chemotherapy in advanced gastric cancer patients compared with that of chemotherapy alone $(19,20)$. The results of these studies therefore suggested that alternate mechanisms of resistance to anti-EGFR antibodies existed in gastric cancer patients.

Numerous key molecules are involved in the EGFR signal transduction pathway, which is also able to cross-talk with other signaling pathways. In addition to K-ras and BRAF, other molecules influence EGFR signaling pathways, including C-Met and the insulin-like growth factor receptor-I (IGF-IR) signaling pathway (21-23). IGF-IR is a receptor tyrosine kinase, which is overexpressed in numerous types of tumor, such as gastrointestinal carcinomas (24-26). IGF-IR becomes autophosphorylated following the binding of ligands, which 
stimulates its tyrosine kinase activity and subsequently activates downstream signaling pathways (27). These pathways include the Ras/Raf/mitogen-activated protein kinase and phosphoinositide 3-kinase/Akt pathways, which are the primary downstream mediators of EGFR signaling (28). This therefore suggested that IGF-IR may modulate the sensitivity of gastric cancer cells to anti-EGFR antibodies.

Resistance to cetuximab was reported to be associated with overactivation of baseline IGF-IR in human nasopharyngeal carcinoma cells; in addition, the inhibition of baseline IGF-IR activation increased sensitivity to cetuximab in cutaneous squamous cell carcinoma (29). However, the involvement of cetuximab in the activation of the IGF-IR pathway and inhibition of the EGFR pathway as well as the role of IGF-IR signaling in cetuximab resistance in gastric cancer cells has remained to be elucidated.

The non-receptor tyrosine kinase c-steroid receptor co-activator ( $\mathrm{Src}$ ) was reported to have a crucial role in IGF-IR signaling. Numerous studies have indicated that Src may be an upstream signaling molecule of IGF-IR and EGFR in kidney cells and epididymal cells $(30,31)$. By contrast, certain studies have shown that IGF-IR acts upstream of Src in human prostate cancer DU145 and breast cancer cells $(32,33)$. Src has also been implicated in chemotherapy resistance in gastric cancer (34). However, the involvement of Src in the regulation of IGF-IR signal transduction and thereby cetuximab sensitivity in gastric cancer cells has remained to be elucidated.

The aim of the present study was to investigate the role of cetuximab in the induction of IGF-IR and Src activation in gastric cancer cells in order to determine the mechanisms underlying cetuimab resistance.

\section{Materials and methods}

Reagents and antibodies. Cetuximab was obtained from Merck KGaA (Darmstadt, Germany). Src inhibitor 4-amino -5-(4-chlorophenyl)-7-(dimethylethyl)pyrazolo[3,4-d] pyrimidine (PP2) was obtained from Sigma (St. Louis, MO, USA). IGF-IR inhibitor OSI-906 was purchased from SelleckBio (Houston, TX, USA). The following antibodies: Anti-EGFR polyclonal antibody, anti-phospho-EGFR (Tyr1068) polyclonal antibody, anti-phospho-Akt (Ser473) polyclonal antibody, anti-IGF-IRmonoclonal antibody, anti-phospho-Src (Y416) polyclonal antibody and anti-phospho-IGF-IR (Tyr1131) polyclonal antibody, were purchased from Cell Signaling Technology, Inc.(Danvers, MA, USA). The following antibodies: Anti- $\beta$-actin polyclonal antibody, anti-Akt monoclonal antibody, anti-extracellular signal-regulated kinase (ERK)1/2 polyclonal antibody, anti-c-Src monoclonal antibody and anti-phospho-ERK1/2 (Tyr202/ Tyr204) polyclonal antibody, were purchased from Santa Cruz Biotechnology, Inc. (Dallas, TX, USA).

Cell cultures. Gastric cancer SGC7901 and MGC803 cells were purchased from the Cell Bank of Type Culture Collection of the Chinese Academy of Sciences (Shanghai, China). Mutations were not located in exons 19 or 21 of the EGFR gene in the two gastric cancer cell lines. The cells were cultured in RPMI-1640 medium (Gibco-BRL, Grand Island, NY, USA) containing 10\% heat-inactivated fetal bovine serum(FBS; Gibco-BRL), $100 \mathrm{U} / \mathrm{ml}$ penicillin and $100 \mu \mathrm{g} / \mathrm{ml}$ streptomycin (Life Technologies, Inc., Carlsbad, CA, USA) at $37^{\circ} \mathrm{C}$ under an atmosphere of $95 \%$ air and $5 \% \mathrm{CO}_{2}$. Cells were routinely subcultured every two to three days and all cells used for experimental procedures were in the logarithmic growth phase.

Small interfering RNA (siRNA) transfections. IGF-IR siRNAs wereobtainedfromShanghaiGemmapharmaceuticaltechnology Co., Ltd (Shanghai, China). IGF-IR siRNA was synthesized using the primer 5'-GCATGGTAGCCGAAGATTT-3'. Lipofectamine $^{\circledR} 2000$ was diluted dropwise into RPMI 1640 and incubated at room temperature for $5 \mathrm{~min}$. IGF-IR siRNA was then added to the diluted Lipofectamine ${ }^{\circledR} 2000$ and incubated for $20 \mathrm{~min}$. Following $48 \mathrm{~h}$ of transient transfection, cells were analyzed using western blot analysis.

Cell viability assay. Cell viability was measured using an MTT assay. Cells were seeded at 3x104/well in 96-well plates and incubated overnight. Cells were then exposed to increasing doses of cetuximab $(0.01,0.1,1.0$ and $10 \mu \mathrm{g} / \mathrm{ml})$ for $24 \mathrm{~h}$; following which, $25 \mu \mathrm{l} \mathrm{MTT}$ solution $(5 \mathrm{mg} / \mathrm{ml})$ was added to each well and the cells were incubated for $4 \mathrm{~h}$ at $37^{\circ} \mathrm{C}$. The cell culture medium was then removed and the cells were lyzed in $200 \mu \mathrm{l}$ dimethylsulphoxide. Optical density was measured at $570 \mathrm{~nm}$ using a microplate reader (Bio-Rad 550; Bio-Rad Laboratories, Hercules, CA, USA).

Western blot analysis. Cells were washed twice with ice-cold phosphate-buffered salineand solubilizedin $1 \%$ Tritonlysisbuffer [1\% Triton X-100 (Sigma-Aldrich, St. Louis, MO, USA); 50 mM Tris-Cl, pH 7.4; 150 mM NaCl; 10 mM EDTA; 100 mM NaF (all purchased from Sinopharm Chemical Reagent, Shanghai, China); $1 \mathrm{mM} \mathrm{Na} \mathrm{VO}_{4} ; 1 \mathrm{mM}$ phenylmethylsulfonyl fluoride; and $2 \mu \mathrm{g} / \mathrm{ml}$ aprotinin (all purchased from Sigma-Alrich)] on ice and then quantified using the Lowry method (35). Cell lysate proteins were separated using SDS-PAGE and electrophoretically transferred onto a nitro-cellulose membrane (Immoblin-P; Millipore, Bedford, MA, USA). Membranes were blocked using $5 \%$ skimmed milk in trimethyl benzene sulfonyl tetrazole buffer (10 mM Tris-C1, pH 7.4; 150 mM NaCl; 0.1\% Tween 20; all purchased from Sinopharm Chemical Reagent) at room temperature for $2 \mathrm{~h}$ and incubated with anti-EGFR, anti-IGF-IR, anti-c-Src, anti-ERK1/2, anti-Akt, anti- $\beta$-Actin, anti-phosphor-EGFR(Tyr1068), anti-phospho-IGF-IR (Tyr1131), anti- phosphor-Src (Y416), anti-phospho-ERK 1/2 (Tyr202/ Tyr204) or anti-phospho-Akt (Ser473) primary antibodies at $4^{\circ} \mathrm{C}$ overnight. The secondary anti-rabbit or mouse monoclonal antibodies (Santa Cruz Biotechnology, Inc.) antibodies (dilution, 1:800) were then added for $30 \mathrm{~min}$ at room temperature. Proteins were detected using an enhanced chemiluminescence reagent (SuperSignal Western Pico Chemiluminescent Substrate; Pierce Biotechnology, Rockford, IL, USA) and visualized using the Electrophoresis Gel Imaging Analysis System (DNR Bio-Imaging Systems, Ltd., Jerusalem, Israel).

Colony-forming assay. In brief, 300 cells per well were seeded onto 12 -well plates. Following adherence to the plates, cells were exposed to $10 \mu \mathrm{g} / \mathrm{ml}$ cetuximab, PP2 and OSI-906. On day 14, clones were air dried without RPMI-1640, then stained for 10 min with Giemsa stain (Sigma-Aldrich). The clones 


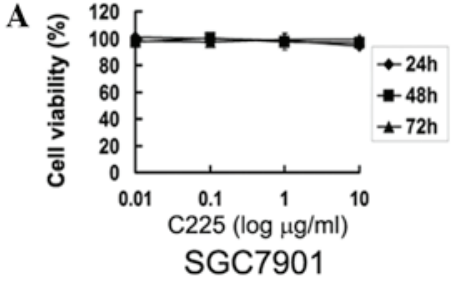

C

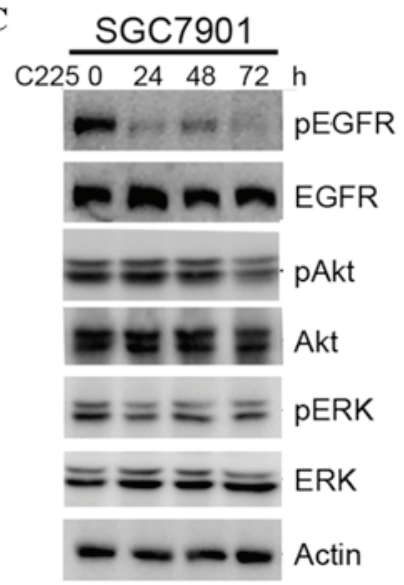

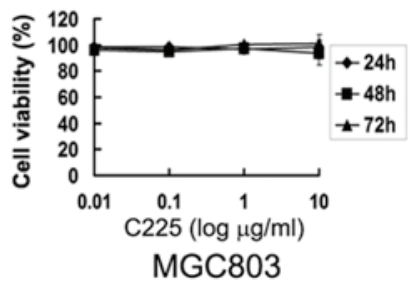

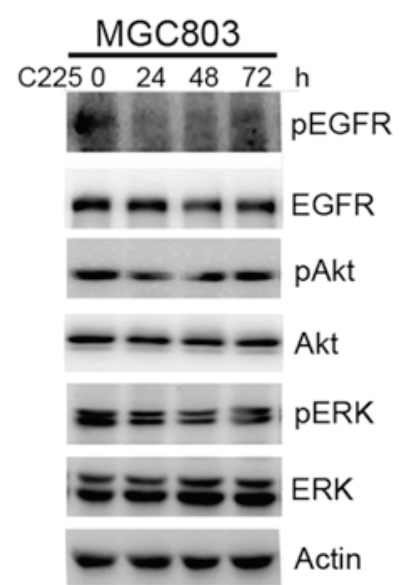

B
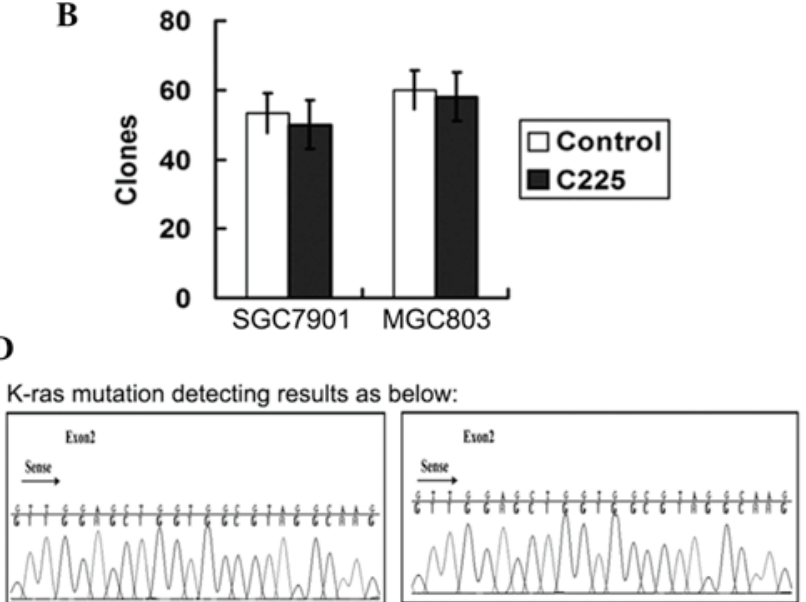

BRAF-exon 15 (V600E) mutation detecting results as below:

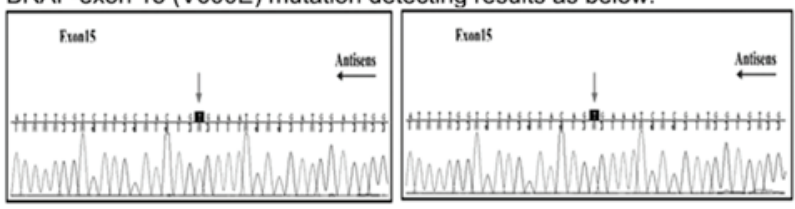

SGC7901
MGC803

Figure 1. Effects of cetuximab on cell viability, colony formation and EGFR signaling pathways in two gastric cancer cell lines. (A) SGC7901 and MGC803 cells were treated with cetuximab $(0.01,0.1,1$ and $10 \mu \mathrm{g} / \mathrm{ml})$ for 24,48 and $72 \mathrm{~h}$. Cell viability was measured using an MTT assay. (B) The two cell lines were exposed to $10 \mu \mathrm{g} / \mathrm{ml}$ cetuximab for 14 days and the colony formation was analyzed. (C) Western blot analysis of the EGFR signaling pathways of SGC7901 and MGC803 cells treated with $10 \mu \mathrm{g} / \mathrm{ml}$ cetuximab for 2, 6 and $24 \mathrm{~h}$. (D) Primer sequences for mutation analysis of K-ras and BRAF. EGFR, epidermal growth factor receptor; ERK, extracellular signal-related kinase; p, phosphorylated; C225, cetuximab.

were then washed with running water and air dried again. Clones in each well were counted and images were captured using inverted microscopy (M021; Olympus, Tokyo, Japan).

Statistical analysis. All experiments were performed in triplicate. Values are expressed as the mean \pm standard deviation. Statistical comparisons were made by Student's t-test. SPSS 16.0 software was used for statistical analysis (International Business Machines, Armonk,NY, USA) and $\mathrm{P}<0.05$ was considered to indicate a statistically significant difference between values.

\section{Results}

Gastric cancer cell lines are resistant to cetuximab. In order to evaluate the sensitivity of gastric cancer cell lines to cetuximab, SGC7901 and MGC803 cells were treated with increasing concentrations of cetuximab $(0.01,0.1,1$ and $10 \mu \mathrm{g} / \mathrm{ml})$ for 24 , 48 and $72 \mathrm{~h}$. Following treatment with cetuximab, the two cell lines exhibited minimal growth inhibition $(<10 \%)$, which therefore indicated that the cells were cetuximab-resistant (Fig. 1A) and the maximal dose of $10 \mu \mathrm{g} / \mathrm{ml}$ cetuximab was therefore used for the subsequent experiments. As shown in Fig. 1B, the colony forming ability of gastric cancer cells was not affected by cetuximab treatment. Furthermore, in order to determine whether cetuximab had a role in blocking EGFR tyrosine kinase activation, the effect of cetuximab treatment on EGFR, ERK and Akt phosphorylation was examined. Cells were incubated with $10 \mu \mathrm{g} / \mathrm{ml}$ cetuximab for 2,6 and $24 \mathrm{~h}$. The results demonstrated a marked decrease in EGFR and ERK phosphorylation; however, Akt phosphorylation remained unchanged (Fig. 1C).
In addition, following a mutation analysis of $K$-ras (codons 12 and 13) and $B R A F$ (exon 15, V600E) genes, no point mutations were observed in the two cell lines. This therefore indicated that cetuximab resistance was not associated with the mutation of these genes (Fig. 1D). Overall, these results suggested that an alternative pathway mediated cetuximab resistance via activation of Akt in gastric cancer cells.

Cetuximab induces activation of IGF-IR and Src in gastriccancer cells. SGC7901 and MGC803 cells were exposed to $10 \mu \mathrm{g} / \mathrm{ml}$ cetuximab for $0.5,2,6,16$ and $24 \mathrm{~h}$. Western blot analysis revealed that IGF-IR phosphorylation was notably increased in the two cell lines, with peak activation detected at $6 \mathrm{~h}$. Increased Src phosphorylation was also observed in MGC803 and SGC7901 cells, with peak activation detected at 6 and $16 \mathrm{~h}$, respectively (Fig. 2). This suggested that cetuximab may have induced the activation of IGF-IR and Src in gastric cancer cells.

Inhibition of IGF-IR activation or expression increases sensitivity of gastric cancer cells to cetuximab and reduces Src phosphorylation. In order to determine whether IGF-IR signaling induced cetuximab resistance, SGC7901 and MGC 803 cells were treated with $10 \mu \mathrm{g} / \mathrm{ml}$ cetuximab in combination with the tyrosine kinase dual insulin receptor and IGF-IR inhibitor OSI-906 $(10 \mu \mathrm{M})$ for 2 and $6 \mathrm{~h}$. OSI-906 inhibited the cetuximab-induced phosphorylation of Src, IGF-IR and Akt in the two cell lines; however, ERK activation was not altered (Fig. 3A). Cetuximab treatment in combination with OSI-906 decreased cell viability in SCG7901 and MGC803 cells, respectively, by $\sim 25$ and $27 \%$ compared to treatment with cetuximab alone (Fig. 3B). Furthermore, a colony-forming assay of 

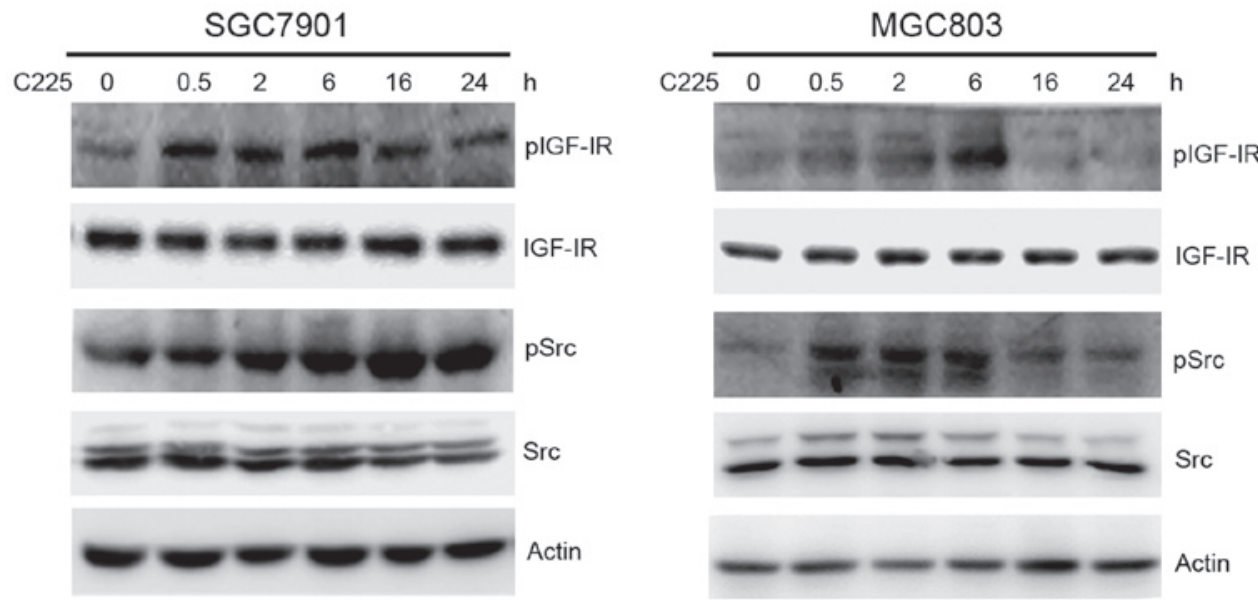

Figure 2. Cetuximab activates IGF-IR and Src. Cells were treated with $10 \mu \mathrm{g} / \mathrm{ml}$ cetuximab for $0.5,2,6,16$ and $24 \mathrm{~h}$. Western blot analysis was then used to detect protein expression levels of IGF-IR and Src. $\beta$-actin was used as an internal control. IGF-IR, insulin-like growth factor receptor 1; Src, steroid receptor co-activator; p, phosphorylated; C225, cetuximab.

A

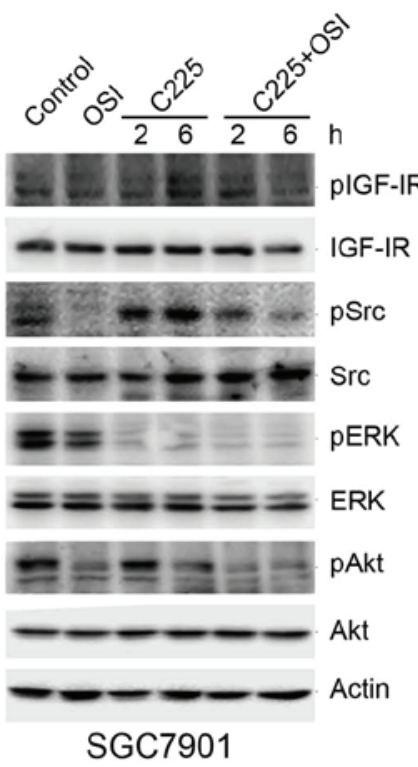

B

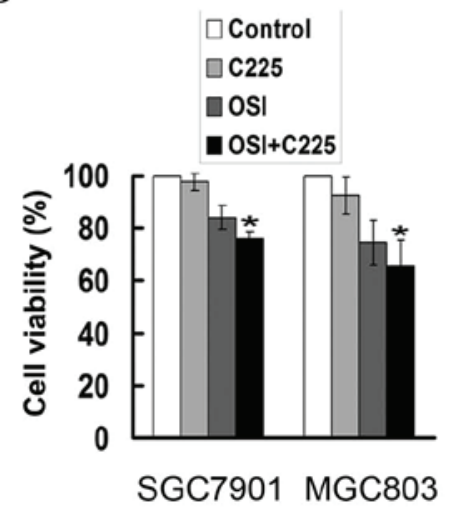

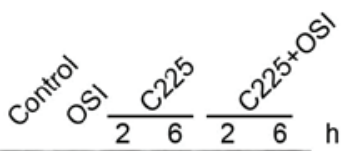

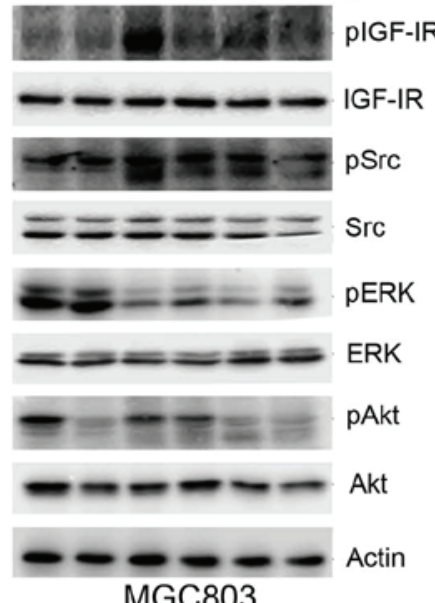

MGC803

C

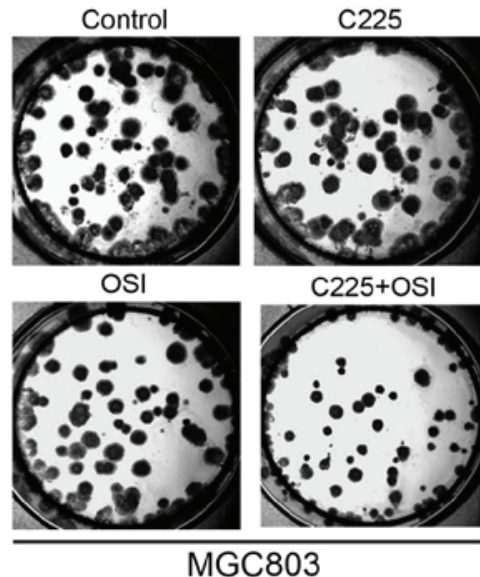

Figure 3. OSI-906 suppresses IGF-IR and Src phosphorylation and enhances the growth inhibitory effects of cetuximab in gastric cancer cells. (A) SGC7901 and MGC803 cells were pretreated with or without the IGF-IR inhibitor OSI-906 $(10 \mu \mathrm{M})$ for $1 \mathrm{~h}$ and then incubated with $10 \mu \mathrm{g} / \mathrm{ml}$ cetuximab for 2 and $6 \mathrm{~h}$. Western blot analysis was then used to detect protein expression levels of phosphorlyated and non-phosphorlyated IGF-IR, Src, ERK and Akt. (B) SGC7901 and MGC803 cells were incubated with $10 \mu \mathrm{g} / \mathrm{ml}$ cetuximab with or without $10 \mu \mathrm{M}$ OSI-906 for $48 \mathrm{~h}$. Cell viability was then assessed using an MTT assay. ${ }^{*} \mathrm{P}<0.05$ treament with combination cetuximab and OSI-906 vs. cetuximab alone. (C) Cells were treated with $10 \mu \mathrm{g} / \mathrm{ml}$ cetuximab and $10 \mu \mathrm{M}$ OSI-906 alone or in combination for 14 days and a colony forming assay was performed. IGF-IR, insulin-like growth factor receptor 1; Src, steroid receptor co-activator; ERK, extracellular signal-related kinase; p, phosphorylated; C225, cetuximab; OSI, OSI-906. 

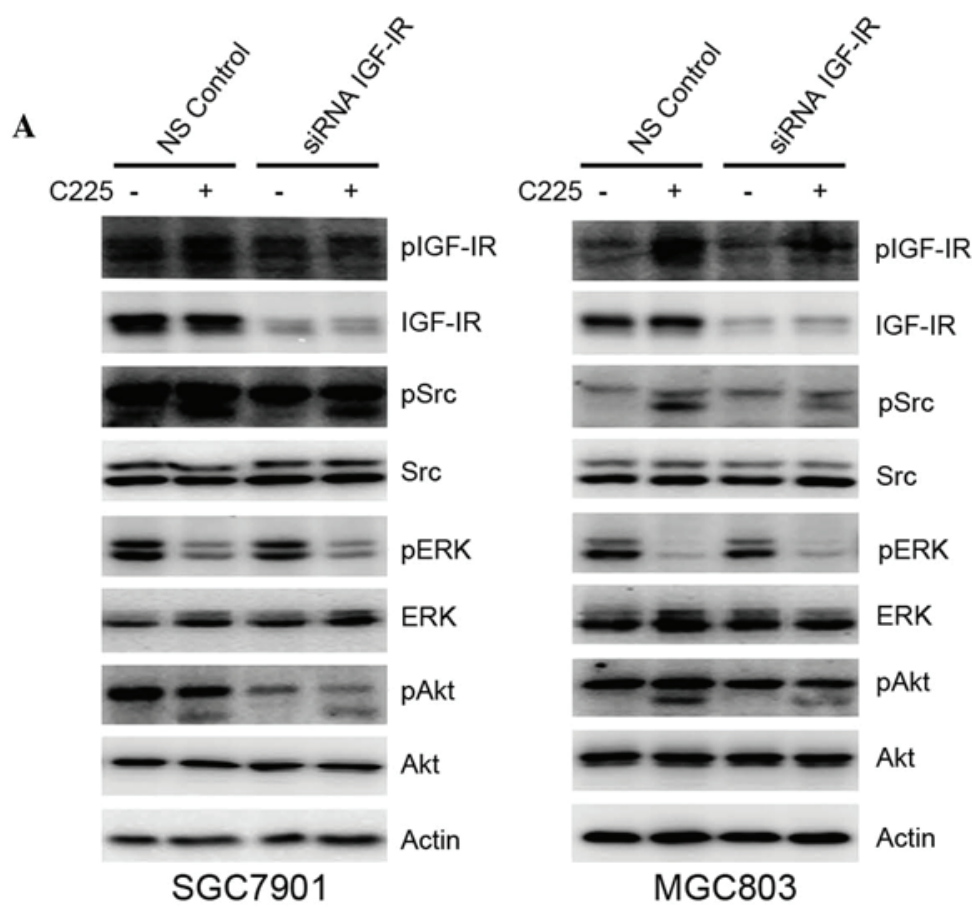

B

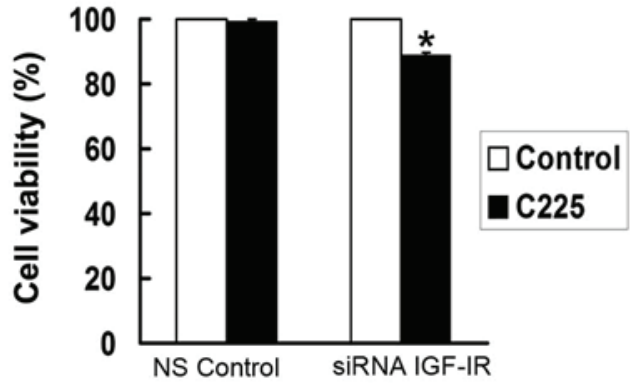

Figure 4. Knockdown of IGF-IR expression reduces cetuximab-induced Src and Akt phosphorylation as well as enhances cellular proliferation inhibition rates in gastric cancer cells. SGC7901 and MGC803 cells were transiently transfected with IGF-IR siRNAs for $48 \mathrm{~h}$, followed by $10 \mu \mathrm{g} / \mathrm{ml}$ cetuximab for $2 \mathrm{~h}$. (A) Western blot analysis was used to detect the phosphorylation of IGF-IR, Src, ERK and Akt. (B) Cell viability was assessed using an MTT assay. "P<0.05, IGF-IR siRNA cells vs. NS control. IGF-IR, insulin-like growth factor receptor 1; Src, steroid receptor co-activator; ERK, extracellular signal-related kinase; p, phosphorylated; C225, cetuximab; siRNA, small interfering RNA; NS, non-silenced.

MGC803 cells revealed that treatment with cetuximab in combination with OSI-906 produced fewer and smaller colonies than treatment with cetuximab alone (Fig. 3C).

The effect of downregulated IGF-IR gene expression on downstream signaling in gastric cancer cells was examined using IGF-IR-specific siRNAs. As shown in Fig. 4A, western blot analysis was used to confirm the knockdown of IGF-IR. Following exposure to $10 \mu \mathrm{g} / \mathrm{ml}$ cetuximab for $2 \mathrm{~h}$, IGF-IR-depleted cells exhibited reduced expression of phosphorylated IGF-IR, Src and Akt; however, ERK phosphorylation remained unchanged (Fig. 4A). Cells transfected with IGF-IR siRNAs demonstrated significantly reduced survival rates compared to that of the control cells following exposure to cetuximab for $48 \mathrm{~h}$ (Fig. 4B). These results therefore indicated that cetuximab-induced IGF-IR activation was responsible for cetuximab resistance and that Src acted downstream of IGF-IR in gastric cancer cell lines.

Inhibition of Src restores cetuximab sensitivity and represses IGF-IR phosphorylation in gastric cancer cells. In order to investigate the association between Src and IGF-IR, gastric cancer cells were pretreated with the Src inhibitor PP2 $(10 \mu \mathrm{M})$ alone or in combination with cetuximab for 2 and $6 \mathrm{~h}$. Activation of IGF-IR was then assessed using western blot analysis. The results revealed that following treatment with PP2, cetuximab-mediated IGF-IR phosphorylation was markedly decreased (Fig. 5A). In addition, gastric cancer cell viability was significantly reduced following cetuximab treatment in combination with PP2 compared to that of cetuximab treatment alone (Fig. 5B). Furthermore, the combination treatment reduced colony formation in MGC803 cells relative to that of treatment with cetuximab alone (Fig. 5C). These results therefore showed that cetuximab-induced activation of IGF-IR was inhibited following the PP2-induced inhibition of Src activation, indicating that there may be a positive feedback loop between IGF-IR and Src.

\section{Discussion}

Numerous studies have confirmed that the primary mechanism of cetuximab resistance was via $K$-ras and $B R A F$ gene mutations (36-39). In addition, cetuximab-sensitive gastric cancer cell lines were reported to significantly reduce EGFR activation following cetuximab treatment compared with cetuximab-resistant cells (40). Another study demonstrated that cetuximab failed to inhibit phosphorylation of EGFR pathways in a cetuximab-resistant head and neck squamous cell cancer cell line (41). The results of the present study indicated that cetuximab resistance occurred in gastric cancer SGC7901 and MGC803 cells expressing wild-type K-ras and BRAF. However, these two cell lines exhibited reduced activation of EGFR and ERK following cetuximab exposure, whereas Akt activation was not affected. It was therefore suggested that other pathways may be involved in Akt activation, thereby mediating cetuximab resistance in gastric cancer cells.

It is widely accepted that EGFR is able to cross-talk with other signaling factors (42-45). A recent study demonstrated that tumor necrosis factor-related apoptosis-inducing ligand (TRAIL) was able to activate the EGFR pathway during TRAIL-induced apoptosis in gastric cancer cells (46). Morgillo et al (47) reported that the EGFR tyrosine kinase inhibitor erlotinib induced heterodimerization of EGFR/IGF-IR, with activation of IGF-IR and its downstream 
A
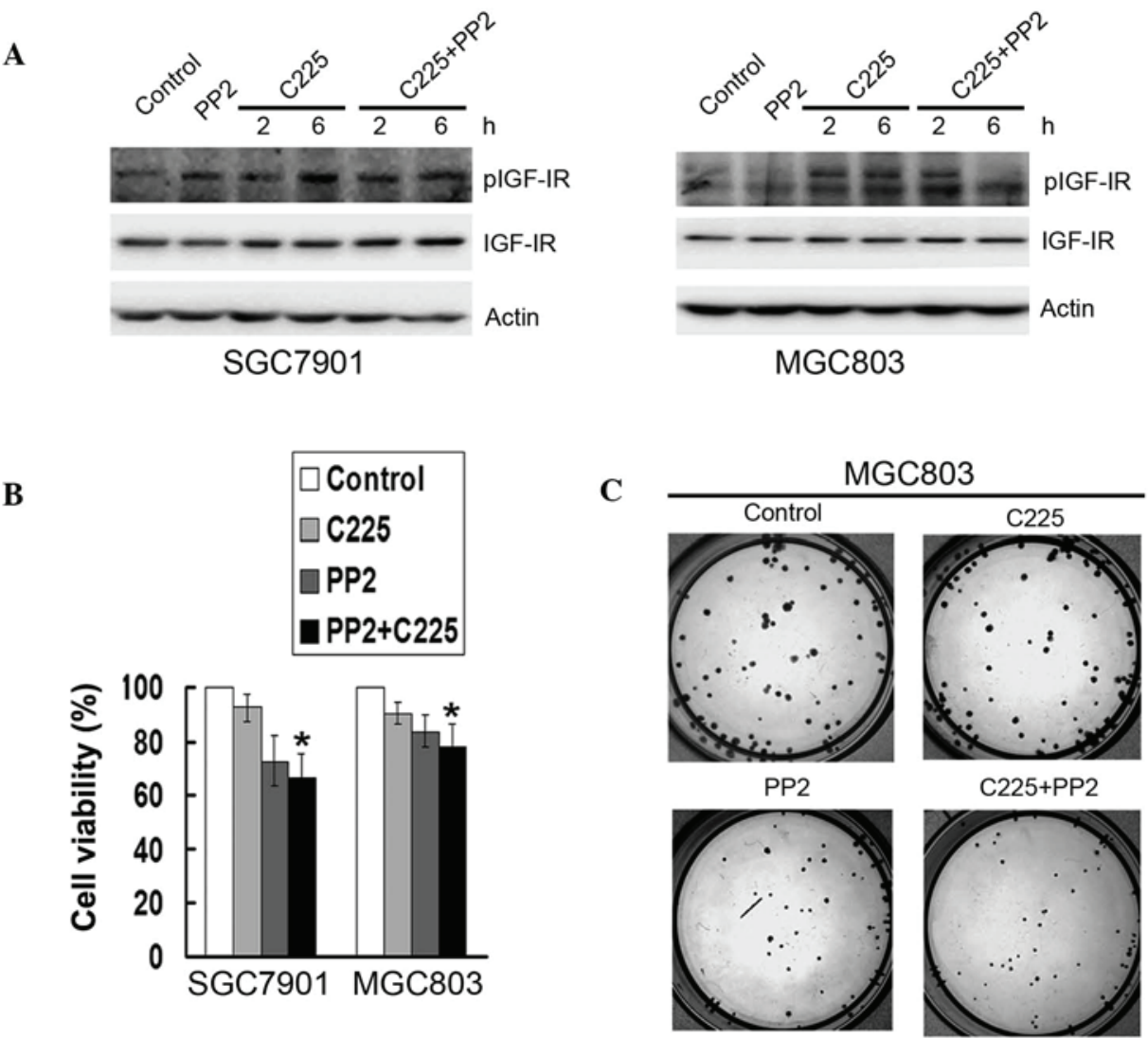

Figure 5. PP2 suppresses IGF-IR phosphorylation and increases the growth inhibitory effect of cetuximab in gastric cancer cells. SGC7901 and MGC803 cells were treated with or without the Src inhibitor PP2 $(10 \mu \mathrm{M})$ for $1 \mathrm{~h}$ prior to the addition of $10 \mu \mathrm{g} / \mathrm{ml}$ cetuximab for $2 \mathrm{~h}$ and $6 \mathrm{~h}$. (A) Western blot analysis was performed to determine the expression levels of IGF-IR and pIGF-IR. (B) Cell viability was assessed using an MTT assay. "P $<0.05$, treatment with combination cetuximab and PP2 vs. cetuximab alone. (C) Following 14 days of treatment a colony forming assay was performed. IGF-IR, insulin-like growth factor receptor 1; p, phosphorylated; C225, cetuximab; PP2, 4-amino-5-(4-chlorophenyl)-7-(dimethylethyl)pyrazolo[3,4- $d$ ]pyrimidine.

mediator Akt in NSCLC cells; in addition, overexpression of IGF-IR has also been observed in numerous types of human cancers (48) and was shown to be involved in cisplatin resistance (49). Furthermore, it was reported that baseline activation of IGF-IR was correlated with cetuximab resistance (29). The present study found that baseline levels of phosphorylated IGF-IR in gastric cancer cells were not increased; however, following exposure to cetuximab there was a gradual increase in levels of IGF-IR phosphorylation. Furthermore, treatment with the IGF-IR inhibitor OSI-906 or IGF-IR siRNAs inhibited activation of IGF-IR and Akt as well as increased the sensitivity of gastric cancer cells to cetuximab. This therefore indicated that cetuximab-induced IGF-IR and Akt activation were involved in cetuximab resistance in gastric cancer.

In order to further investigate the regulation of cetuximab-induced IGF-IR activation, Scr activation was then assessed in the present study. Peterson et al (50) reported that IGF-IR was a substrate for v-Src. Src activation was found to occur upstream of IGF-IR transactivation as well as stimulate IGF-dependent proliferation in HEK293 cells and pancreatic carcinoma cells $(30,51)$. By contrast, it was reported that IGF induced Src activation in vascular smooth muscle cells (52). Therefore, the upstream and downstream association between Src and IGF-IR required further elucidation. In the present study, cetuximab was shown to simultaneously induce the activation of IGF-IR and Src. In turn, inhibition of IGF-IR activation prevented the activation of Src, while inhibition of Src activation inhibited the activation of IGF-IR. This therefore provided evidence for a positive feedback loop between IGF-IR and Src. Furthermore, inhibiting the activation of IGF-IR as well as Src improved gastric cancer-cell sensitivity to cetuximab, therefore indicating that cetuximab induced the activation of IGF-IR and Src, which resulted in cetuximab resistance in SGC7901 and MGC803 gastric cancer cells.

In conclusion, the results of the present study demonstrated that cetuximab blocked EGRF while concurrently inducing activation of IGF-IR and Src. Evidence was provided for a positive feedback loop between Src and IGF-IR, which activated the Akt signaling pathway downstream of EGFR, therefore mediating cetuximab resistance in gastric cancer cells. These present study contributed evidence towards an explanation for the mechanisms underlying cetuximab resistance in gastric cancer cells that retain wild-type $K$-ras and $B R A F$ genes. In addition, the results of the present study indicated that inhibition of IGF-IR activation may be an effective mechanism by which cetuximab sensitivity may be enhanced in order to improve the effectiveness of combination chemotherapy in gastric cancer patients.

\section{Acknowledgements}

The present study was supported by grants from the Chinese National Foundation of National Sciences (nos. 81201802, 
$81172369,81172198,81372485$ and 81372546), Specialized Research Fund for the Doctoral Program of Higher Education (nos. 20102104120008 and 20112104110005) and National Science and Technology Major Project (no. 2013ZX09303002).

\section{References}

1. Parkin DM, Bray F, Ferlay J and Pisani P: Global cancer statistics, 2002. CA Cancer J Clin 55: 74-108, 2005.

2. Van Custem E, Moiseyenko VM, Tjulandin S, et al; V325 Study Group: Phase III study of docetaxel and cisplatin plus fluorouracil compared with cisplatin and fluorouracil as first-line therapy for advanced gastric cancer: a report of the V325 Study Group. J Clin Oncol 24: 4991-4997, 2006.

3. Cunningham D, Starling N, Rao S, et al; Upper Gastrointestinal Clinical Studies Group of the National Cancer Research Institute of the United Kingdom: Capecitabine and oxaliplatin for advanced esophagogastric cancer. N Engl J Med 358: 36-46, 2008.

4. Koizumi W, Narahara H, Hara T, et al: S-1 plus cisplatin versus $\mathrm{S}-1$ alone for first-line treatment of advanced gastric cancer (SPIRITS trial): a phase III trial. Lancet Oncol 9: 215-221, 2008

5. Kang YK, Kang WK, Shin DB, et al: Capecitabine/cisplatin versus 5-fluorouracil/cisplatin as first-line therapy in patients with advanced gastric cancer: a randomised phase III noninferiority trial. Ann Oncol 20: 666-673, 2009.

6. Ajani JA, Rodriguez W, Bodoky G, et al: Multicenter phase III comparison of cisplatin/S-1 with cisplatin/infusional fluorouracil in advanced gastric or gastroesophageal adenocarcinoma study: the FLAGS trial. J Clin Oncol 28: 1547-1553, 2010.

7. Bang YJ, Van Custem E, Feyereislova A, et al: Trastuzumab in combination with chemotherapy versus chemotherapy alone for treatment of HER2-positive advanced gastric or gastro-oesophageal junction cancer (ToGA): a phase 3 , open-label, randomised controlled trial. Lancet 376: 687-697, 2010.

8. Ohtsu A, Shah MA, Van Custem E, et al: Bevacizumab in combination with chemotherapy as first-line therapy in advanced gastric cancer: a randomized, double-blind, placebo-controlled phase III study. J Clin Oncol 29: 3968-3976, 2011.

9. Gómez-Martin C, Garralda E, Echarri MJ, et al: HER2/neu testing for anti-HER2-based therapies in patients with unresectable and/or metastatic gastric cancer. J Clin Pathol 65:751-757, 2012.

10. Van Custem E, Köhne CH, Hitre E, et al: Cetuximab and chemotherapy as initial treatment for metastatic colorectal cancer. N Engl J Med 360: 1408-1417, 2009.

11. Specenier P and Vermorken JB: Cetuximab in the treatment of squamous cell carcinoma of the head and neck. Expert Rev Anticancer Ther 11: 511-524, 2011

12. Pirker R, Pereira JR, Szczesna A, et al; FLEX Study Team: Cetuximab plus chemotherapy in patients with advanced non-small-cell lung cancer (FLEX): an open-label randomised phase III trial. Lancet 373: 1525-1531, 2009.

13. Pinto C, Di Fabio F, Barone C, et al: Phase II study of cetuximab in combination with cisplatin and docetaxel in patients with untreated advanced gastric or gastro-oesophageal junction adenocarcinoma (DOCETUX study). Br J Cancer 101: 1261-1268, 2009.

14. Lee KH, Lee JS, Suh C, et al: Clinicopathologic significance of the K-ras gene codon 12 point mutation in stomach cancer. An analysis of 140 cases. Cancer 75: 2794-2801, 1995.

15. Davies H, Bignell GR, Cox C, et al: Mutations of the BRAF gene in human cancer. Nature 417: 949-954, 2002

16. Moehler M, Mueller A, Trarbach T, et al; German Arbeitsgemeinschaft Internistische Onkologie: Cetuximab with irinotecan, folinic acid and 5-fluorouracil as first-line treatment in advanced gastroesophageal cancer: a prospective multi-center biomarker-oriented phase II study. Ann Oncol 22: 1358-1366, 2011.

17. Lordick F, Luber B, Lorenzen S, et al: Cetuximab plus oxaliplatin/ leucovorin/5-fluorouracil in first-line metastatic gastric cancer: a phase II study of the Arbeitsgemeinschaft Internistische Onkologie (AIO). Br J Cancer 102: 500-505, 2010.

18. Pinto C, Di Fabio F, Siena S, et al: Phase II study of cetuximab in combination with FOLFIRI in patients with untreated advanced gastric or gastroesophageal junction adenocarcinoma (FOLCETUX study). Ann Oncol 18: 510-517, 2007.
19. Lordick F, Kang YK, Chung HC, et al; Arbeitsgemeinschaft Internistische Onkologie and EXPAND Investigators: Capecitabine and cisplatin with or without cetuximab for patients with previously untreated advanced gastric cancer (EXPAND): a randomised, open-label phase 3 trial. Lancet Oncol 14: 490-499, 2013.

20. Waddel T, Chau I, Cunningham D, et al: Epirubicin, oxaliplatin, and capecitabine with or without panitumumab for patients with previously untreated advanced oesophagogastric cancer (REAL3): a randomised, open-label phase 3 trial. Lancet Oncol 14: 481-489, 2013.

21. Engelman JA, Zejnullahu K, Mitsudomi T, et al: MET amplification leads to gefitinib resistance in lung cancer by activating ERBB3 signaling. Science 316: 1039-1043, 2007.

22. Bean J, Brennan C, Shih JY, et al: MET amplification occurs with or without T790M mutations in EGFR mutant lung tumors with acquired resistance to gefitinib or erlotinib. Proc Natl Acad Sci USA 104: 20932-20937, 2007.

23. Chakravarti A, Loeffler JS and Dyson NJ: Insulin-like growth factor receptor I mediates resistance to antiepidermal growth factor receptor therapy in primary human glioblastoma cells through continued activation of phosphoinositide 3-kinase signaling. Cancer Res 62: 200-207, 2002.

24. Ouban A, Muraca P, Yeatman T and Coppola D: Expression and distribution of insulin-like growth factor-1 receptor in human carcinomas. Hum Pathol 34: 803-808, 2003.

25. Pavelić K, Kolak T, Kapitanović S, et al: Gastric cancer: the role of insulin-like growth factor 2 (IGF 2) and its receptors (IGF 1R and M6-P/IGF 2R). J Pathol 201: 430-438, 2003.

26. Shiraishi T, Mori M, Yamagata M, et al: Expression of insulin-like growth factor 2 mRNA in human gastric cancer. Int J Oncol 13: 519-523, 1998.

27. Baserga R: The IGF-I receptor in cancer research. Exp Cell Res 253: 1-6, 1999

28. Yu H and Rohan T: Role of the insulin-like growth factor family in cancer development and progression. J Natl Cancer Inst 92: 1472-1489, 2000.

29. Zuo Q, Shi M, Li L, et al: Development of cetuximab-resistant human nasopharyngeal carcinoma cell lines and mechanisms of drug resistance. Biomed Pharmacother 64: 550-558, 2010.

30. Oligny-Longpré G, Corbani M, Zhou J, et al: Engagement of $\beta$-arrestin by transactivated insulin-like growth factor receptor is needed for V2 vasopressin receptor-stimulated ERK1/2 activation. Proc Natl Acad Sci USA 109: E1028-E1037, 2012.

31. Hamzeh M and Robaire B: Androgens activate mitogen-activated protein kinase via epidermal growth factor receptor/insulin-like growth factor 1 receptor in the mouse PC-1 cell line. J Endocrinol 209: 55-64, 2011.

32. Zhang S, Huang WC, Li P, et al: Combating trastuzumab resistance by targeting SRC, a common node downstream of multiple resistance pathways. Nat Med 17: 461-469, 2011.

33. Ligęza J, Ligęza J and Klein A: Growth factor/growth factor receptor loops in autocrine growth regulation of human prostate cancer DU145 cells. Acta Biochim Pol 58: 391-396, 2011.

34. Mayer EL and Krop IE: Advances in targeting SRC in the treatment of breast cancer and other solid malignancies. Clin Cancer Res 16: 3526-3532, 2010.

35. Peterson GL: A simplification of the protein assay method of Lowry et al. which is more generally applicable. Anal Biochem 83: 346-356, 1977.

36. Lièvre A, Bachet JB, Le Corre D, et al: KRAS mutation status is predictive of response to cetuximab therapy in colorectal cancer. Cancer Res 66: 3992-3995, 2006.

37. Di Fiore F, Blanchard F, Charbonnier F, et al: Clinical relevance of KRAS mutation detection in metastatic colorectal cancer treated by Cetuximab plus chemotherapy. Br J Cancer 96: 1166-1169, 2007.

38. Di Nicolantonio F, Martini M, Molinari F, et al: Wild-type $\mathrm{BRAF}$ is required for response to panitumumab or cetuximab in metastatic colorectal cancer. J Clin Oncol 26: 5705-5712, 2008.

39. Brose MS, Volpe P, Feldman M, et al: BRAF and RAS mutations in human lung cancer and melanoma. Cancer Res 62: 6997-7000, 2002.

40. Heindl S, Eggenstein E, Keller S, et al: Relevance of MET activation and genetic alterations of KRAS and E-cadherin for cetuximab sensitivity of gastric cancer cell lines. J Cancer Res Clin Oncol 138: 843-858, 2012.

41. Rebucci M, Peixoto P, Dewitte A, et al: Mechanisms underlying resistance to cetuximab in the HNSCC cell line: Role of AKT inhibition in bypassing this resistance. Int J Oncol 38: 189-200, 2011. 
42. Cordero JB, Stefanatos RK, Myant K, et al: Non-autonomous crosstalk between the Jak/Stat and Egfr pathways mediates Apc1-driven intestinal stem cell hyperplasia in the Drosophila adult midgut. Development 139: 4524-4535, 2012.

43. Cavallo RA, Cox RT, Moline MM, et al: Drosophila Tcf and Groucho interact to repress Wingless signalling activity. Nature 395: 604-608, 1998.

44. Brantjes H, Roose J, van De Wetering M and Clevers H: All Tcf HMG box transcription factors interact with Groucho-related co-repressors. Nucleic Acids Res 29: 1410-1419, 2001

45. Hasson P and Paroush Z: Crosstalk between the EGFR and other signalling pathways at the level of the global transcriptional corepressor Groucho/TLE. Br J Cancer 96 (Suppl): R21-R25, 2007.

46. Xu L, Zhang Y, Liu J, et al: TRAIL-activated EGFR by Cbl-b-regulated EGFR redistribution in lipid rafts antagonizes TRAIL-induced apoptosis in gastric cancer cells. Eur J Cancer 48: 3288-3299, 2012.

47. Morgillo F, Woo JK, Kim ES, et al: Heterodimerization of insulin-like growth factor receptor/epidermal growth factor receptor and induction of survivin expression counteract the antitumor action of erlotinib. Cancer Res 66: 10100-10111, 2006.
48. Pollak M: Insulin-like growth factor physiology and cancer risk. Eur J Cancer 36: 1224-1228, 2000.

49. Cortés-Sempere M, de-Miguel MP, Pernía O, et al: IGFBP-3 methylation-derived deficiency mediates the resistance to cisplatin through the activation of the IGFIR/Akt pathway in non-small cell lung cancer. Oncogene 32: 1274-1283, 2013.

50. Peterson JE, Kulik G, Jelinek T, et al: Src phosphorylates the insulin-like growth factor type I receptor on the autophosphorylation sites. Requirement for transformation by src. J Biol Chem 271: 31562-31571, 1996.

51. Flossmann-Kast BB, Jehle PM, Hoeflich A, et al: Src stimulates insulin-link growth factor I (IGF-I)-dependent cell proliferation by increasing IGF-I receptor number in human pancreatic carcinoma cells. Cancer Res 58: 3551-3554, 1998.

52. Lieskovska J, Ling Y, Badley-Clarke J and Clemmons DR: The role of Src kinase in insulin-like growth factor-dependent mitogenic signaling in vascular smooth muscle cells. J Biol Chem 281: 25041-25053, 2006. 